\title{
The role of water and hygiene project of Integrated Regional Support Programme (IRSP) in district swabi, khyber pakhtunkhwa
}

\begin{abstract}
This internship report conducted in 2016, with the objectives to learn the work environment in the development organization and to study the role of water and hygiene project of Integrated Regional Support Programme (IRSP) in district Swabi, Khyber Pakhtunkhwa. For this, data was collected by the internee and the field staff of the host organization. Total households residing in the camp were selected as the respondents for this study which is 130 . Descriptive statistics were used for analysis of the data. Result of the study revealed that $38.09 \%$ were female and $37.86 \%$ are male and lies in the age group of above 20 years while data responding literacy level reveals that $30.15 \%$ of the respondents were literate, mostly having primary level of education. The data reveals that $49.05 \%$ buffaloes were kept by the household. Further data shows that $35.87 \%$ of the people are using their own private sources of water, while $64.13 \%$ of the people are using public sources of water. At household level $33 \%$ water are store in water cooler for drinking purpose, while $43 \%$ water are store in jerry cans for other purposes. Further data reveals that $76.15 \%$ people cleaning their drinking water storage source daily. The data reveals that $15.39 \%$ treat their water, while $84.61 \%$ not treat their water due to $53.64 \%$ source are clean. $66.92 \%$ have accessibility to safe drinking water, while $33.08 \%$ have no accessibility to safe drinking water. Further data shows that $35.13 \%$ households suffered from diarrhea lied in the age group of above 16 year, while $1.53 \%$ is died due to diarrhea. It is found that $34.62 \%$ food quality is the reason of diarrhea, while expenditure on diarrhea cure is $34 \%$ which is $2000-5000$. Further data shows that $18.40 \%$ wash hand with soap after working with animals, while $11.33 \%$ wash hand without soap after working with animals. It is found that $15.39 \%$ households have hand washing place, while $84.61 \%$ have no hand washing place. The data reveals that $23.08 \%$ have available soap at hand washing place, while $76.92 \%$ have no available soap at hand washing place.
\end{abstract}

Volume 2 Issue 4 - 2018

\author{
Muhammad Ismail Khan, Shaista Naaz \\ Department of Rural development, University of Agriculture \\ Peshwar, Pakistan
}

Correspondence: Muhammad Ismail Khan, Department of Rural development, University of Agriculture Peshwar, Pakistan, Tel 03336754432, Email ismailaup707@gmail.com

Received: February 20, 2018 | Published: August 21, 2018

\section{Introduction}

Safe drinking water and hygienic sanitation are prerequisites for health. Unfortunately, there are about 884 million people in the world who do not get their drinking water from improved sources, and about 2.6 billion people are living without adequate sanitation. ${ }^{1}$ globally, the levels of availability and accessibility of safe drinking water are measured by standard indicators that depend on the presence of proper sanitary sources. These improved drinking water sources include household connection, public standpipe, borehole condition, protected dug well, protected spring, and rain water collection. Sources that may represent potentially contaminated drinking water include unprotected wells, unprotected springs, rivers or ponds, vender-provided water and tanker truck water. ${ }^{2}$ Researchers and health experts usually explain that insufficient supply of clean and safe drinking water is the main cause of diseases in developing countries.

In Pakistan, only 66 percent of the population is considered to have access to safe drinking water with huge disparities between urban and rural areas and among provinces/regions. Safe drinking water in rural areas is a precious commodity. Inadequate quantity and quality of the supply of drinking water results in a high incidence of water related diseases, which in turn, increase morbidity and mortality rates and pose a major threat to the survival and development of children. ${ }^{3}$ International monitoring organizations define "access" to safe drinking water as the availability of at least 20 liters per person per day from an "improved" source within 1 kilometer of the user's dwelling, ${ }^{4}$ but such sources are rarely available in some areas. According to the Global Water Supply and Sanitation Assessment report by WHO and UNICEF, in Pakistan, around 30 percent of illnesses and 40 percent of deaths are attributed to inadequate water quality. Water quality in areas of poor sanitation and poor hygiene is related to the density of population-where, population is dense under such circumstances there is likely to be more contamination of water sources. ${ }^{1}$ It has been estimated that on yearly basis, more than 3 million people in Pakistan suffer from cholera and other diarrheal diseases caused by poor water quality and about 20-40 percent of hospital beds in Pakistan are occupied by patients suffering from water-borne diseases.

In Pakistan, the mortality rate for children under age five is 101 deaths per 1,000 children.4 Diarrhea is responsible for 11 percent of deaths for children under five years. The main causes of diarrhea in children are unsafe drinking water, inadequate sanitation, and poor hygiene. Diarrhea is also a significant cause of under nutrition and can affect a child's overall health. Unsafe drinking water also has a disproportionate effect on the poor. The combination of consumption of unsafe water and poor hygiene practices causes hardships, as it leads to high-cost treatments for waterborne illnesses and decreases both economic productivity and educational achievement (due to reduced 
school attendance by children). The presence of improved sanitation facilities is very low in rural areas-about 35 percent. According to the Demographic Health Survey, ${ }^{5} 22$ percent of Pakistani children under age five had an episode of diarrhea during the two-week period before the survey, and about 30 percent of Pakistanis practice open defecation (above the world average, which is 18 percent). ${ }^{6}$

According to the Federal Bureau of Statistics, ${ }^{7}$ in Khyber Pakhtunkhwa province, lack of access to safe water and poor sanitation are key contributors to under-nutrition. Both lead to a chronic cycle of illness and under-nutrition, and infants and young children are particularly susceptible. The province has marginally lower levels of safe water usage by household $(70 \%)$ as compared to the national level $(87 \%)$. Use of hygienic sanitation facilities is also slightly lower $(62 \%)$ than the national level (66\%). In January 2010, a survey by Khyber Pakhtunkhwa ${ }^{8}$ Provincial Reforms Program show that the water source situation in southern Khyber Pakhtunkhwa is inadequate because the land water aquifers are either quite deep (more than 500 $\mathrm{ft}$ ) or the existing water is salty and hence unhealthy for drinking. As a consequence there is an elevated dependence on high-risk sources including ponds, insecure springs and/or local streams which are open to contamination.

Both the planning and undertaking of comprehensive research on water and hygiene promotion issues among refugee populations has remained a challenge. Reasons include security restrictions, complex operational conditions, scarce resources, understaffing or high staff turn-over, the difficulty of undertaking thorough measurements during emergency situations and the fact that refugee camps are often forcibly located on marginal lands. Hence, these very real constraints hinder efforts by water and health professionals to systematically document and build on lessons learnt in order to improve services in these areas in subsequent refugee operations. It has also meant that all the available time and resources are needed simply keeping water supply and sanitation control mechanisms functioning and so the need for research is overlooked. This internship report aims to outline the current water and hygiene situation in refugee camp of district Sawabi. A base line survey of IRSP at the refugee household level was used to investigate the aforementioned problem.

\section{Objectives of the internship report}

The overall objective of this internship report is to assess the water and hygiene situation in Barakai camp of district Swabi, Khyber Pakhtunkhwa. The specific objectives are as follow;

1. To assess the existing situation of water and hygiene facilities in the study area

2. To investigate water-borne diseases in the study area

3. To find out the problems of refugee households with respect to water and hygiene facilities

4. To suggest recommendations on the basis of findings

\section{Internship report methodology}

This chapter explains the methodology used to answer the internship research objectives and the actual work performs by the Integrated Regional Support Program (IRSP) at the field level. This chapter comprises of universe of the study, sample selection, sample size, sample respondents, data collection and its analysis.

\section{Universe of the study}

The study was carried out in Barakai camp of district Swabi, Khyber Pakhtunkhwa. The Barakai camp is comprised of 130 Afghan refugees, families. The study involved the Afghan refugees, families living in the target camp. Afghan refugees of this camp were served as population of the study.

\section{Sample selection}

\section{Sample respondents}

Total households residing in the camp were selected as the respondents for this study which 130 .

\section{Data collection}

For collection of data, face to face interview schedule was used which is developed in english language for academic purpose, but exercised in pushto language for understanding of the respondents, to solicit the required information correctly. The internee and the field staff of the host organization conducted interview and each respondent was interviewed on individual basis. In total, 130 household heads were respondents to the survey.

\section{Data analysis}

After the collection of data, it was analyzed by using descriptive statistics by using Micro Soft Excel 2007.

\section{Results and discussion}

This chapter deals with results and discussion with respect to the "Assessment of water and hygiene situation in Barakai camp of district Swabi, Khyber Pakhtunkhwa" executed by Integrated Regional Support Programme (IRSP).

\section{Age wise distribution of the sampled respondents}

Age is an important factor in the demographic analysis of an individual's life because the responsibilities of a person vary with the age. Table 1 show that $27.60 \%, 34.42 \%$ and $37.98 \%$ household members lied in the age groups of less than 5 year, 5-20 year, and of above 20 year, respectively. The data reveal that majority of the household members lie in the age group of above 20 year which shows that most of the population in the camp was of young age.

Table I Age wise distribution of the sampled respondents

\begin{tabular}{lll}
\hline Age group (Years) & Frequency & Percentage \\
\hline Less than 5 & 36 & 27.6 \\
May-20 & 45 & 34.42 \\
Above 20 & 49 & 37.98 \\
Total & 130 & 100
\end{tabular}

\section{Distribution of sampled respondents by educational level}

Education plays an important role in individual personality grooming and development and also plays a vital role in nation' future building. The data in Table 2 shows that $28.57 \%$ of the household were illiterate, while $30.15 \%$ were literate. Of the total literate respondents, $25.40 \%, 8.73 \%, 5.55 \%$ and $1.60 \%$ had primary, secondary, higher secondary and above secondary level education, respectively. This shows that literacy rate of the area was 30 percent which is low. The data also further reveals that most of the people having primary level of education which further show the low level of educational status of the respondents. Moreover, the least number of respondents had above higher secondary level education. 
Table 2 Distribution of the sampled respondents by educational level

\begin{tabular}{lll}
\hline Educational Level & Frequency & Percentage \\
\hline Illiterate & 36 & 28.57 \\
Literate & 38 & 30.15 \\
Primary & 32 & 25.4 \\
Secondary & 11 & 8.73 \\
Higher secondary & 7 & 5.55 \\
Above secondary level & 2 & 1.6 \\
Total & 126 & 100 \\
\hline
\end{tabular}

\section{Sex-wise age distribution of the sampled households}

Table 3 indicates that there were total of 674 household members, of which $338(50.14 \%$ ) were male and $336(49.86 \%)$ were female members. Out of the total male, $28.40 \%, 33.74 \%$ and $37.86 \%$ were in the age of less than 5 year, 5-20 year, and of above 20 year, respectively. Similarly, out of the total female family members, $26.78 \%$, $35.11 \%$ and $38.09 \%$ was in the age group of less than 5 year, 5-20 year, and of above 20 year, respectively. It shows that majority of the households are female and lies in the age group of 5-20 years.

Table 3 Sex-wise age distribution of the sampled households

\begin{tabular}{|c|c|c|c|c|c|}
\hline \multirow{2}{*}{$\begin{array}{l}\text { Age grou- } \\
\text { p(years) }\end{array}$} & \multicolumn{2}{|c|}{$\begin{array}{l}\text { Male household } \\
\text { members }\end{array}$} & \multicolumn{2}{|c|}{$\begin{array}{l}\text { Female household } \\
\text { members }\end{array}$} & \multirow{2}{*}{ Total } \\
\hline & Frequency & Percentage & Frequency & Percentage & \\
\hline Less than 5 & 96 & 28.4 & 90 & 26.78 & 186 \\
\hline 43952 & 114 & 33.74 & 118 & 35.12 & 232 \\
\hline Above 20 & 128 & 37.86 & 128 & 38.1 & 256 \\
\hline Total & 338 & 100 & 336 & 100 & 674 \\
\hline
\end{tabular}

\section{Livestock Possession}

Livestock rearing is an important source of rural livelihoods and serves as an important asset at household level. Livestock provide milk, milk products (yogurt, butter, butter oil etc.) and other byproducts. Table 4 shows that, 106 different types of livestock were kept by the sampled respondents at household level. Out of the total livestock types, $49.05 \%, 2.83 \%, 36.8 \%$ and $11.23 \%$ were buffaloes, cows, goats /sheeps and other, respectively. The results revealed that buffalos were the major type of livestock followed by goats/sheep in the study area.

Table 4 Different types of livestock kept by the sampled respondents

\begin{tabular}{lll}
\hline Livestock Types & Frequency & Percentage \\
\hline Buffaloes & 52 & 49.05 \\
Cows & 3 & 2.83 \\
Goats /Sheep & 39 & 36.8 \\
Others & 12 & 11.32 \\
Total & 106 & 100 \\
\hline
\end{tabular}

\section{Drinking water sources in the study area}

Four types of drinking water sources were found in the study area which includes piped, protected dug well, unprotected dug well, and hand pump. Table 5 shows the data regarding drinking water sources in the study area. It was found that that about $46 \%$ of the households were using piped water as the main source of available drinking water. About $28 \%$ of the households reported that they obtain drinking water from the hand pumps. Among the households, $17 \%$ were getting drinking water from the protected dug wells. However, $9 \%$ of the households explained that they obtain water from unprotected dug well. The data revealed that majority of the households obtained piped water followed by hand pumped water.

Table 5 Sources of drinking water in the study area

\begin{tabular}{lll}
\hline Water sources & Frequency & Percentage \\
\hline Piped & 60 & 46 \\
Protected dug well & 22 & 17 \\
Unprotected dug well & 12 & 9 \\
Hand pump & 36 & 28 \\
Total & 130 & 100 \\
\hline
\end{tabular}

\section{Monthly tariff of water}

Table 6 indicates that $15 \%$ households used free water with no tariff while $11 \%, 22 \%$ and $52 \%$ households paid a monthly water tariff of Rs. 50-150, Rs. 151-250 and above Rs. 250, respectively. The results revealed that drinking water is not free of cost for majority of the households in the camp and it was also found that majority of households were paying a monthly water tariff of above Rs. 250 .

Table 6 Monthly tariff of water in the study area

\begin{tabular}{lll}
\hline Amount (Rs.) & Frequency & Percentage \\
\hline None/Free & 19 & 15 \\
$50-150$ & 14 & 11 \\
$151-250$ & 29 & 22 \\
Above 250 & 68 & 52 \\
Total & 130 & 100
\end{tabular}

\section{Drinking water fetching responsibility among the sampled households}

Table 7 shows the data regarding drinking water fetching responsibility among the sampled households. It was found that $4 \%$, $90 \%$ and $6 \%$ of men, women and children were involved in water fetching in the study area. It shows that majority of women have drinking water fetching responsibility in the study area. It is common observation that in developing countries and especially refugee women fetches water for drinking and other domestic purpose.

Table 7 Drinking water fetching responsibility among the sampled households

\begin{tabular}{lll}
\hline Household member & Frequency & Percentage \\
\hline Men & 5 & 4 \\
Women & 117 & 90 \\
Children & 8 & 6 \\
Total & 130 & 100 \\
\hline
\end{tabular}

\section{Drinking water fetching frequency per day}

Table 8 denotes that $6 \%, 56 \%$, and $37 \%$ households fetched water once, twice and more than twice per day in the study area. The results 
indicated that majority of the households fetch drinking water twice per day followed by more than twice a day. It further reveals that the households used fresh water for drinking that's why they fetched drinking water more than once in day.

Table 8 Drinking water fetching frequency per day

\begin{tabular}{lll}
\hline Response category & Frequency & Percentage \\
\hline Once & 8 & 6 \\
Twice & 74 & 57 \\
More than twice & 48 & 37 \\
Total & 130 & 100
\end{tabular}

\section{Water storage methods at household Level}

Method of water storage at household level is divided in to seven categories; container with lid, container without lid, water tank on roof, drum, jeri cans, water cooler, and pitcher. Table 9 shows that at household level drinking water was stored in the above mentioned storage containers. The result shows that $6.31 \%, 1.94 \%, 0.49 \%$, $13.6 \%, 32.52 \%, 33 \%, 12.14 \%$, of the households used container with lid, container without lid, water tank on roof, drum, jeri cans, water cooler and pitcher, respectively for drinking water storage at household level. Water for other domestic purposes was stored in container with lid $(4.14 \%)$, container without lid $(5 \%)$, water tank on roof $(3.59 \%)$, drum $(29.53 \%)$, jeri cans $(43 \%)$, water cooler $(5.42 \%)$ and pitcher $(9.32 \%)$. The results indicate that drinking water was mostly stored in jeri cans followed by drum. For domestic purpose, water was also mostly stored in jery cans and drums.

Table 9 Water storage methods at household level

\begin{tabular}{|c|c|c|c|c|c|}
\hline \multirow{2}{*}{$\begin{array}{l}\text { Methods } \\
\text { of water } \\
\text { storage }\end{array}$} & \multicolumn{2}{|c|}{ Drinking water } & \multicolumn{2}{|c|}{$\begin{array}{l}\text { Water for other } \\
\text { domestic use }\end{array}$} & \multirow{2}{*}{ Total } \\
\hline & Frequency & Percentage & Frequency & Percentage & \\
\hline $\begin{array}{l}\text { Container } \\
\text { with lid }\end{array}$ & 13 & 6.31 & 8 & 4.14 & 21 \\
\hline $\begin{array}{l}\text { Container } \\
\text { without lid }\end{array}$ & 4 & 1.94 & 9 & 5 & 13 \\
\hline $\begin{array}{l}\text { Water tank } \\
\text { on roof }\end{array}$ & 1 & 0.49 & 7 & 3.59 & 8 \\
\hline Drum & 28 & 13.6 & 57 & 29.53 & 85 \\
\hline Jeri cans & 67 & 32.52 & 83 & 43 & 150 \\
\hline $\begin{array}{l}\text { Water } \\
\text { cooler }\end{array}$ & 68 & 33 & 11 & 5.42 & 79 \\
\hline Pitcher & 25 & 12.14 & 18 & 9.32 & 43 \\
\hline Total & 206 & 100 & 193 & 100 & 399 \\
\hline
\end{tabular}

\section{Drawing method of drinking water from the storage} source

The drawing method of drinking water from the storage source were divided into four categories dipping a glass/jug or mug, long handle scoop, taps and other. Table 10 shows that $62 \%, 4 \%, 28 \%$ and $6 \%$ households draw drinking water from the storage source by using dipping a glass/jug or mug, long handle scoop, taps, and other, respectively. The results indicate that at household level drinking water was drawn from the storage source by using a glass/mug or jug. The second major drinking water drawing method was the use of taps in the study area.

Table 10 Drawing method of drinking water from the storage source

\begin{tabular}{lll}
\hline Response category & Frequency & Percentage \\
\hline Dipping a glass/jug or mug & 80 & 62 \\
Long handle scoop & 5 & 4 \\
Taps & 37 & 28 \\
Other & 8 & 6 \\
Total & 130 & 100
\end{tabular}

\section{Hand touches while drawing drinking water}

Table 11 represents the data regarding carefulness of drinking water drawl from the water storage source in the study area. It was found that in $34 \%$ household's hands touched while drawing water from the storage source. However in $66 \%$ households hand did not touch the water while drawing it from the storage source. It shows that although majority of the households were careful while drawing drinking water from the storage source still $34 \%$ were not careful. Their hands touched the water thus the chances of water contamination increased which further increase the incidence of water borne diseases in the study area.

Table I I Hand touches while drawing drinking water

\begin{tabular}{lll}
\hline Response category & Frequency & Percentage \\
\hline Yes & 44 & 34 \\
No & 86 & 66 \\
Total & 130 & 100 \\
\hline
\end{tabular}

\section{Cleaning interval of drinking water storage source}

The interval of cleaning of drinking water storage source at household level is divided into four categories; daily, once a week, once a month, and never. Table 12 shows that $76 \%, 15 \%, 7 \%$ and $2 \%$ households clean the drinking water storage source daily, once a week, once a month, and never, respectively. The data reveals that majority of the households clean the drinking water storage source daily which is good to decrease the incidence of water borne diseases. Moreover, majority of the households used jeri cans for drinking water storage so it is quite easy for them to clean it daily.

Table 12 Cleaning interval of drinking water storage source in the study area

\begin{tabular}{lll}
\hline Response category & Frequency & Percentage \\
\hline Daily & 99 & 76 \\
Once a week & 19 & 15 \\
Once a month & 9 & 7 \\
Never & 3 & 2 \\
Total & 130 & 100
\end{tabular}

\section{Reasons of long interval of water storage source cleaning}

Table 13 indicates that $52 \%, 30 \%$ and $18 \%$ households took long intervals for water storage source cleaning due to the reasons of water is already clean, time shortage and no means of cleaning, respectively. the results revealed that the major reason or perception that water is clean prevail in the study area due to which the households took long 
intervals or did not even clean the water storage sources in the study area.

Table I 3 Reasons of long interval of water storage source cleaning

\begin{tabular}{lll}
\hline Response category & Frequency & Percentage \\
\hline Water is clean & 14 & 52 \\
Time shortage & 8 & 30 \\
No means & 5 & 18 \\
Total & 27 & 100
\end{tabular}

\section{Treatment of drinking water}

Treatment of water is very necessary in daily life to avoid water borne diseases and for good health. Table 14 represents the data regarding drinking water treatment at household level. It was found that $15 \%$ of the household treat drinking water while, $85 \%$ did not treated there water. The results indicate that a vast majority of the household did not treat drinking water which further increasing the chances of water borne diseases. The boiling method was mostly used for drinking water treatment.

Table I 4 Treatment of drinking water in the study area

\begin{tabular}{lll}
\hline Response category & Frequency & Percentage \\
\hline Yes & 20 & 15 \\
No & 110 & 85 \\
Total & 130 & 100
\end{tabular}

\section{Reasons of not drinking water treatment}

Table 15 represents the data regarding reasons of not treating drinking water in the study area. a total of five reasons (i.e. doesn't smell, no colour, no taste, source already cleaned and other) were identified due to which households did not treat drinking water. It was found that $6 \%, 2 \%, 22 \%, 54 \%$ and $16 \%$ households were of the view that water have no smell, no colour, no taste, water source are clean and others, respectively. It shows that majority of the households did not treat drinking water due to their perception that water storage source was cleaned so the water will be also clean. The second major reason was that water taste was not disturbed so the water needs no treatment. It overall indicates that households were not aware about the importance of drinking water treatment.

Table I 5 Reasons of not drinking water treatment

\begin{tabular}{lll}
\hline Response category & Frequency & Percentage \\
\hline Doesn't smell & 7 & 6 \\
No colour & 2 & 2 \\
No taste & 24 & 22 \\
Source cleaning & 59 & 54 \\
Others & 18 & 16 \\
Total & 110 & 100
\end{tabular}

\section{Age of household suffered from diarrhea}

Diarrhea disease is common in everywhere which is mainly epidemic and water borne. Table 16 shows that a total of 111 household members were suffered from diarrhea in the study area. Out of the total suffered household members, $34 \%, 31 \%$ and $35 \%$ household members lied in the age group of less than 5 year, 5-16 year and above 16 year, respectively. It shows that majority of the household members suffered from diarrhea lied in the age group of above 16 year.

Table I6 Age of household suffered from diarrhea

\begin{tabular}{lll}
\hline Age group (year) & Frequency & Percentage \\
\hline Less than 5 & 38 & 34 \\
May-16 & 34 & 31 \\
Above 16 & 39 & 35 \\
Total & 111 & 100
\end{tabular}

\section{Death cases due to diarrhea}

Table 17 shows that $1.53 \%$ household reported death cases due to diarrhea and $98.47 \%$ of household reported no death occurrence. Majority of household have not reported death occurrence.

Table 17 Death cases due to diarrhea

\begin{tabular}{lll}
\hline Response category & Frequency & Percentage \\
\hline Yes & 2 & 1.53 \\
No & 128 & 98.47 \\
Total & 130 & 100
\end{tabular}

\section{Treatment methods in case of diarrhea}

Treatment of diarrhea is very important because death occur due to this disease. Table 18 shows treatment methods in case of diarrhea among the sample households. The data reveal that $4 \%, 9 \%, 14 \%$, $8 \%, 9 \%$. $8 \%, 46 \%$ and about $2 \%$ households treated diarrhea by nothing, ORS intake, home-made fluid/drink, pill or syrup, injection, home remedies/herbal medication, consulting a doctor and other, respectively. It was found that majority of the households consulting a doctor in case of diarrhea.

Table 18 Treatment methods in case of diarrhea

\begin{tabular}{lll}
\hline Response category & Frequency & Percentage \\
\hline Nothing & 5 & 4 \\
ORS intake & 12 & 9 \\
Home-made fluid/drink & 18 & 14 \\
Pill or syrup & 11 & 8 \\
Injection & 12 & 9 \\
Home remedies/herbal medication & 10 & 8 \\
Consulting a doctor & 60 & 46 \\
Other & 2 & 2 \\
Total & 130 & 100 \\
\hline
\end{tabular}

\section{Expenditures on diarrhea}

Expenditure on diarrhea cure is divided in to five categories, less than Rs. 500, Rs. 500-2000, Rs. 2001-5000, Rs. 5001-10000, and above Rs. 10000 . Table 19 shows that $10 \%, 28 \%, 34 \%, 13 \%$, and $15 \%$ 
households spend less than Rs. 500, Rs. 500-2000, Rs. 2001-5000, Rs. 5001-10000, and above Rs. 10000, respectively. Majority of the household expend above 10000 on diarrhea cure which is quite high.

Table 19 Expenditures on diarrhea

\begin{tabular}{lll}
\hline Response category & Frequency & Percentage \\
\hline$>500$ & 10 & 10 \\
$500-2000$ & 28 & 28 \\
$2001-5000$ & 34 & 34 \\
$5001-10000$ & 13 & 13 \\
Above 10000 & 15 & 15 \\
Total & 100 & 100 \\
\hline
\end{tabular}

\section{Possible reasons of diarrhea}

Table 20 indicates that $35 \%, 24 \%, 4 \%, 11 \%$, and $27 \%$, households identified the possible reasons of diarrhea food quality, dirty water, food flies, dirty hands and other, respectively. The data reveals that majority of the households have diarrhea due to improper food quality followed by dirty water.

Table 20 Possible reasons of diarrhea

\begin{tabular}{lll}
\hline Response category & Frequency & Percentage \\
\hline Food quality & 45 & 35 \\
Dirty water & 31 & 24 \\
Food flies & 5 & 4 \\
Dirty hands & 14 & 11 \\
Other & 35 & 27 \\
Total & 130 & 100 \\
\hline
\end{tabular}

\section{Time of hand washing with soap or without soap}

The time of hand washing with soap or without soap are divide in to seven categories, before eating, before cooking, after using toilet, after cleaning house, after working with animals, after cleaning the child and other. Table 21 indicate that there were total 163(35.20\%) household wash hand with soap and 300(64.80\%) household wash hand without soap. Out of the total $12.89 \%$ wash hand with soap before eating, and $34 \%$ wash hand without soap before eating, $9.81 \%$ wash hand with soap before cooking, and $17.67 \%$ wash hand without soap before cooking, $36.20 \%$ wash hand with soap after using toilet, and $16.33 \%$ wash hand without soap after using toilet, $10.43 \%$ wash hand with soap after cleaning house, and $10.67 \%$ wash hand without soap after cleaning house, $18.40 \%$ wash hand with soap after working with animals, and $11.33 \%$ wash hand without soap after working with animals, $11.66 \%$ wash hand with soap after cleaning the child, and $8.33 \%$ wash hand without soap after cleaning the child, and $0.61 \%$ wash hand with soap after other working and $1.67 \%$ wash hand without soap after other working.

Table 2 I Time of hand washing with soap or without soap

\begin{tabular}{lccccc}
\hline $\begin{array}{l}\text { Time } \\
\text { of hand } \\
\text { washing }\end{array}$ & Frequency & Percentage & Frequency & Percentage \\
\cline { 3 - 6 } & With soap & & \multicolumn{2}{c}{ Without soap } & Total \\
\hline $\begin{array}{l}\text { Before } \\
\text { eating }\end{array}$ & 21 & 13 & 102 & 34 & 123
\end{tabular}

\begin{tabular}{llllll}
$\begin{array}{l}\text { Before } \\
\text { cooking }\end{array}$ & 16 & 10 & 53 & 18 & 69 \\
\hline $\begin{array}{l}\text { Time } \\
\text { of hand } \\
\text { washing }\end{array}$ & With soap & Frequency & Percentage & Frequency & Percentage \\
\cline { 2 - 6 } & 30 & 18 & Without soap & Total \\
\hline $\begin{array}{l}\text { After } \\
\text { working } \\
\text { with } \\
\text { animals }\end{array}$ & 30 & 34 & 11 & 64 \\
$\begin{array}{l}\text { After } \\
\text { cleaning } \\
\text { the child }\end{array}$ & 19 & 12 & & & \\
$\begin{array}{l}\text { Others } \\
\text { Total }\end{array}$ & 1 & 1 & 25 & 8 & 44 \\
\hline
\end{tabular}

\section{Hand washing place}

Table 22 shows the hand washing place of the household, near the toilet $6.92 \%$, near the kitchen $8.47 \%$ and none $84.61 \%$. Majority of the household have no hand washing place which is $84.61 \%$.

Table 22 Hand washing place

\begin{tabular}{lll}
\hline Response category & Frequency & Percentage \\
\hline Near the toilet & 9 & 6.92 \\
Near the kitchen & $1 \mathrm{I}$ & 8.47 \\
None & 110 & 84.61 \\
Total & 130 & 100
\end{tabular}

\section{Availability of soap at hand washing place}

Availability of soap at hand washing place is very necessary. Table 23 shows that $23.08 \%$ soap is available at hand washing place and $76.92 \%$ soap is not available at hand washing place. Majority of the household have no soap at hand washing place which is $76.92 \%$ due to poverty.

Table 23 Availability of soap at hand washing place

\begin{tabular}{lll}
\hline Response category & Frequency & Percentage \\
\hline Yes & 30 & 23.08 \\
No & 100 & 76.92 \\
Total & 130 & 100 \\
\hline
\end{tabular}

\section{Overall cleanliness of the house}

Overall cleanliness of the house is very important. Table 24 sows that there were total of 780 household members, of which 216 $(27.69 \%)$ were clean the house good, 386(49.49\%) were clean the house average and $178(22.82 \%)$ were clean the house poor. Out of the total good, $20.83 \%, 18.52 \%, 6.94 \%, 17.13 \%, 15.28 \%$ and $21.30 \%$, clean the house, kitchen, latrine, family members, children and water containers, respectively. Similarly, out of the total average, $15.54 \%$, $17.36 \%, 18.66 \%, 16.59 \%, 14.24 \%$ and $17.61 \%$, clean the house, kitchen, latrine, family members, children and water containers, respectively. Similarly, out of the total poor, $14.04 \%, 12.92 \%, 24.15 \%$, $16.30 \%, 23.60 \%$ and $8.99 \%$, clean the house, kitchen, latrine, family members, children and water containers, respectively. It shows that majority of the households clean the house average which is $52.26 \%$. 
Table 24 Overall cleanliness of the house

\begin{tabular}{llllllll}
\hline House portions & Good & Percentage & Average & Percentage & Poor & Percentage & Total \\
\hline House & 45 & 20.83 & 60 & 15.54 & 25 & 14.04 & 130 \\
Kitchen & 40 & 18.52 & 67 & 17.36 & 23 & 12.92 & 130 \\
Latrine & 15 & 6.94 & 72 & 18.66 & 43 & 24.15 & 130 \\
Family members & 37 & 17.13 & 64 & 16.59 & 29 & 16.3 & 130 \\
Children & 33 & 15.28 & 55 & 14.24 & 42 & 23.6 & 130 \\
Water containers & 46 & 21.3 & 68 & 17.61 & 16 & 8.99 & 130 \\
Total & 216 & 100 & 386 & 100 & 178 & 100 & 780 \\
\hline
\end{tabular}

\section{Conclusion}

From the findings of the study it is concluded that most of the households used piped water for drinking. Drinking water was stored in jerry cans which were cleaned on daily basis. Drinking water was drawn from the storage source by dipping mug/jug or glass which increased the chances of water contamination. While drawing water from the water source mostly households were not careful. Water storage sources were mostly cleaned on daily basis with water application. Majority of the households did not treat water to avoid contamination and water borne diseases due to their perception that water is already clean. Most of the household members suffered from diarrhea with including adults and children. Diarrhea was cured by consulting a doctor with high treatment expenditures in the study area.

\section{Acknowledgements}

None.

\section{Conflict of interest}

The author declares that there is no conflict of interest.

\section{References}

1. WHO and UNICEF. Progress on Sanitation and Drinking-Water. WHO/ UNICEF Joint Monitoring Programme for Water Supply and Sanitation; 2010. 59 p.

2. WHO and UNICEF. Meeting the MDG Drinking Water and Sanitation Target: A Mid-Term Assessment of Progress. WHO/UNICEF Joint Monitoring Programme for Water Supply and Sanitation; 2004. 36 p.

3. PES-Pakistan Economic Survey, (2010-11), Health and Nutrition. Ministry of Finance, Government of Pakistan.

4. Josephine F. Access to Safe Drinking Water and Its Impact on Global Economic Growth. USA: HaloSource; 2009. 76 p.

5. USAID. Pakistan Safe Drinking Water and Hygiene Promotion Project Final Report. Bethesda, Maryland: Abt Associates Inc; 2010. 56 p.

6. Pakistan Safe Drinking Water and Hygiene Promotion Project. Final Report. USAID/Pakistan; 2010. 50 p.

7. Federal Bureau of Statistics, (2010-11), Pakistan Social and Living Measurement Survey. Pakistan: Government of Pakistan.

8. Khyber Pakhtunkhwa Provincial Reforms Program. Oxford Policy Management: Policy expertise; 2010. 44 p. 